\title{
Role of land surface processes and diffuse/direct radiation partitioning in simulating the European climate
}

\author{
E. L. Davin and S. I. Seneviratne \\ Institute for Atmospheric and Climate Science, ETH Zurich, Zürich, Switzerland \\ Correspondence to: E. L. Davin (edouard.davin@env.ethz.ch) \\ Received: 4 November 2011 - Published in Biogeosciences Discuss.: 6 December 2011 \\ Revised: 2 April 2012 - Accepted: 10 April 2012 - Published: 11 May 2012
}

\begin{abstract}
The influence of land processes and in particular of diffuse/direct radiation partitioning on surface fluxes and associated regional-scale climate feedbacks is investigated using ERA-40 driven simulations over Europe performed with the COSMO-CLM ${ }^{2}$ Regional Climate Model (RCM). Two alternative Land Surface Models (LSMs), a 2nd generation LSM (TERRA_ML) and a more advanced 3rd generation LSM (Community Land Model version 3.5), and two versions of the atmospheric component are tested, as well as a revised coupling procedure allowing for variations in diffuse/direct light partitioning at the surface, and their accounting by the land surface component.

Overall, the RCM performance for various variables (e.g., surface fluxes, temperature and precipitation) is improved when using the more advanced 3rd generation LSM. These improvements are of the same order of magnitude as those arising from a new version of the atmospheric component, demonstrating the benefit of using a realistic representation of land surface processes for regional climate simulations. Taking into account the variability in diffuse/direct light partitioning at the surface further improves the model performance in terms of summer temperature variability at the monthly and daily time scales. Comparisons with observations show that the RCM realistically captures temporal variations in diffuse/direct light partitioning as well as the evapotranspiration sensitivity to these variations. Our results suggest that a modest but consistent fraction (up to $3 \%$ ) of the overall variability in summer temperature can be explained by variations in the diffuse to direct ratio.
\end{abstract}

\section{Introduction}

The physical, chemical and biological processes acting at the interface between the land surface and the atmosphere influence the Earth's climate at various spatiotemporal scales (e.g., Bonan, 2008; Seneviratne et al., 2010; Arneth et al., 2010). The important role of land-atmosphere interactions was already explicitly recognized during the design of the first climate models, which conceptualized the exchanges of radiation, heat and water between the land and the atmosphere through relatively simple land surface parametrization (e.g., Manabe, 1969). Since then, Land Surface Models (LSMs) have been continuously improved, to a point where they can represent the linkages between energy, water and nutrients cycles within the terrestrial biosphere.

Current Regional Climate Models (RCMs), however, often do not fully reflect the latest advances in LSM development, which is more tightly linked to the development of global models. Indeed, the progress towards global Earth System Models (ESMs) explicitly representing climate-carbon cycle interactions have motivated the use of advanced, biogeochemistry-enabled LSMs within global climate models (Friedlingstein et al., 2006), while regional climate modelling studies have been comparatively more focused on atmospheric processes and often relied on much simpler LSMs (Giorgi, 2006).

However, recent efforts have pointed out the potential added value of integrating more comprehensive LSMs into RCMs. The coupling between RAMS (Regional Atmospheric Modelling System) and the CENTURY biogeochemistry model showed that the phenological cycle of vegetation can significantly affect water and energy fluxes and thus regional climate (Lu et al., 2001). RAMS was also coupled to 
the $\mathrm{SiB}$ (Simple Biosphere) model in order to simulate diurnal and synoptical variations in $\mathrm{CO}_{2}$ fluxes and atmospheric $\mathrm{CO}_{2}$ concentrations over North America (Denning et al., 2003; Wang et al., 2007). The coupling between RegCM3 (Regional Climate Model version 3) and CLM3 (Community Land Model version 3) improved the simulated characteristics of the monsoon over West Africa (Steiner et al., 2009). RegCM3 was also coupled to IBIS (Integrated Biosphere Simulator) which led to a better simulation of latent heat flux over North America, although biases were increased for surface temperature and sensible heat flux (Winter et al., 2009). Finally, in a coupling between WRF3 (Weather Research and Forecasting model version 3) and CLM3.5 (Community Land Model version 3.5), Subin et al. (2011) illustrated the usefulness of RCMs to study the impact of land cover change on climate at the regional scale.

The COSMO-CLM model version 4.0 has been recently coupled to CLM3.5 in order to improve the representation of land surface processes in the context of regional climate simulations (Davin et al., 2011). In this new model configuration termed COSMO-CLM ${ }^{2}$, CLM3.5 replaces TERRA_ML, the native LSM included in COSMO-CLM. When using CLM3.5 instead of TERRA_ML, Davin et al. (2011) found an overall improvement in the simulated climate over Europe, in particular for cloud cover, temperature and precipitation. This was due to a more realistic simulation of surface fluxes and more specifically a better partitioning between sensible and latent heat. However, important biases still remained in the model, such as a large underestimation of surface net shortwave radiation (Davin et al., 2011).

Here, we present an updated version of COSMO-CLM ${ }^{2}$ benefiting from a new version of the atmospheric component and from an improved description of the partitioning between diffuse and direct light at the surface. We extend the work of Davin et al. (2011) by testing the two alternative LSMs in the context of two different versions of the atmospheric component, thus allowing to quantify the relative influence of land versus atmospheric processes. We furthermore aim at providing new insights into processes influencing land-atmosphere exchanges, namely by examining the role of diffuse/direct radiation partitioning at the surface. Observations indeed suggest that the ratio of diffuse to direct light influences plant photosynthesis, photosynthesis being enhanced under diffuse light conditions (Gu et al., 2003; Alton et al., 2007). This effect may have strong implications for the global carbon cycle (Mercado et al., 2009). On the other hand, evapotranspiration can also be affected by the light environment (Knohl and Baldocchi, 2008), since photosynthesis is tightly coupled to transpiration through stomatal control. Offline LSM simulations have suggested a possible impact of diffuse/direct radiation partitioning on land hydrology (Oliveira et al., 2011), but the possible feedbacks on climate have yet to be investigated. CLM3.5 explicitly distinguishes between diffuse and direct light in its canopy scheme and also represents the coupling between photosynthesis and transpiration, thus allowing to simulate the impact of light conditions on surface fluxes. Whereas our previous version of COSMO-CLM ${ }^{2}$ assumed a fixed diffuse to direct ratio for incoming shortwave radiation (Davin et al., 2011), we test here the effect of allowing for variations in diffuse/direct ratio in the model.

\section{Methods}

\subsection{COSMO-CLM ${ }^{2}$}

COSMO-CLM $^{2}$ (Davin et al., 2011) couples the COSMOCLM model (Rockel et al., 2008) to CLM3.5 (Oleson et al., 2004, 2008). COSMO-CLM is a non-hydrostatic RCM jointly used by the COnsortium for Small-scale Modelling (COSMO) and the Climate Limited-area Modelling Community (CLM-Community). CLM3.5 is a state of the art LSM representing the hydrological, biogeophysical and biogeochemical processes determining the exchanges of radiation, heat, water and carbon between the land and the atmosphere.

The native LSM in COSMO-CLM, TERRA_ML (Grasselt et al., 2008, and references therein), has been retained within COSMO-CLM ${ }^{2}$ so that with the same atmospheric model either CLM3.5 or TERRA_ML can be used, allowing to quantify the influence of the LSM on the simulated climate. A description of the differences between CLM3.5 and TERRA_ML is provided by Davin et al. (2011).

Several options related to the dynamical core or the physical packages are available in the model. Here we use the second-order leapfrog scheme for the time integration. Vertical turbulent mixing is parametrized according to a level 2.5 closure using Turbulent Kinetic Energy (TKE) as a prognostic variable (Mellor and Yamada, 1974, 1982). For moist convection, the mass flux scheme of Tiedtke (1989) is used. Large-scale precipitation is parametrized with a fourcategory 1-moment cloud-ice scheme including cloud and rain water, snow and ice. CLM3.5 is used without carbonnitrogen dynamics and ecosystem dynamics.

\subsection{Summary of model improvements}

New developments have been introduced in COSMO-CLM ${ }^{2}$ compared to the previous version (Davin et al., 2011). First, the atmospheric component has been upgraded to a newer version. Second, a modification of the coupling procedure regarding diffuse and direct fluxes from the atmospheric component to CLM3.5 has been introduced.

COSMO-CLM ${ }^{2}$ has been initially developed based upon version 4.0 of COSMO-CLM (Davin et al., 2011). For this study, we upgraded COSMO-CLM to version 4.8. A number of modifications have been introduced between versions 4.0 and 4.8 some of which are reflected in Baldauf et al. (2011). Beside various bug corrections, the most notable improvement between these two versions relates to changes made to the Tiedtke cumulus convection scheme (Tiedtke, 1989). The newest version allows for a mixed water-ice phase when 
clouds condense (previously condensation occurred either as water or ice depending on air temperature) and an instantaneous evaporation of detrained convective clouds is not anymore assumed. Additionally, a number of other modifications apply to configurations not used in this study (e.g., Runge-Kutta dynamics, subgrid-scale orography, data assimilation) and are therefore not discussed here. Note also that TERRA_ML, the native LSM in COSMO-CLM, has not been modified between versions 4.0 and 4.8 .

The coupling procedure regarding shortwave radiative fluxes has been revised to provide the LSM with both diffuse and direct beam fluxes from the atmospheric model. Note that this procedure is relevant only when CLM3.5 is used as the land component, since TERRA_ML does not make use of diffuse and direct fluxes in its calculations. CLM3.5 distinguishes between diffuse and direct radiation in its canopy radiative transfer scheme. An important assumption in this scheme is the two-leaf canopy approach in which the canopy is made up of a sunlit part (receiving both direct and diffuse light) and a shaded part (receiving only diffuse light). Photosynthesis and stomatal conductance are calculated separately for sunlit and shaded leaves and are thus affected by the amount of diffuse versus direct light (Thornton and Zimmermann, 2007). However, if the direct and diffuse radiation components are not explicitly provided, CLM3.5 uses the total incoming shortwave radiation and assumes a fixed $30 / 70 \%$ (diffuse/direct) partitioning. This procedure is applied in the previous version of COSMO-CLM ${ }^{2}$ (Davin et al., 2011). Here, we modified the coupling procedure in such a way that the surface incoming diffuse and direct fluxes calculated by the $\delta$-two-stream atmospheric radiative transfer scheme in COSMO-CLM (Ritter and Geleyn, 1992) are provided explicitly to CLM3.5 instead of the total incoming shortwave flux.

\subsection{Experiments}

Five different experiments, summarized in Table 1, are analysed in this study. Experiments v4.0-TERRA_ML, v4.0CLM3.5, v4.8-TERRA_ML and v4.8-CLM3.5 allow us to isolate the effect of the LSM (CLM3.5 versus TERRA_ML) on the simulated regional climate in the context of two different versions of the atmospheric component (4.0 versus 4.8). Experiment v4.8-CLM3.5-dif includes the modification to the treatment of diffuse and direct radiative fluxes. Therefore, comparing v4.8-CLM3.5-dif with v4.8-CLM3.5 (with fixed $30 \%$ diffuse and $70 \%$ direct) allow us to quantify the impact of introducing a spatially and temporally varying diffuse/direct partitioning in the model.

As in Davin et al. (2011), all five experiments use a horizontal resolution of $0.44^{\circ}(\sim 50 \mathrm{~km})$ with 32 atmospheric levels in the vertical and a time step of $240 \mathrm{~s}$. The model domain encompasses the entire European continent, including parts of northern Africa and of Russia. The simulations cover the period from 1980 to 2006 . ERA40 reanalysis data
(Uppala et al., 2005) are used as lateral boundary conditions, except for the years 2002-2006 for which ECMWF operational forecast analyses are employed. $\mathrm{CO}_{2}, \mathrm{CH}_{4}$ and $\mathrm{N}_{2} \mathrm{O}$ concentrations are prescribed according to observed historical trends. The first 6 years are used as spin-up time and only the following years (1986-2006) are analysed.

\subsection{Evaluation datasets}

We use 2-meter temperature, precipitation and total cloud cover from the Climate Research Unit (CRU) TS3.1 global $0.5^{\circ}$ gridded dataset (Mitchell and Jones, 2005). The International Satellite Cloud Climatology Project (ISCCP) D2 dataset at $280 \times 280 \mathrm{~km}$ resolution (Rossow and Schiffer, 1999) is also used as an alternative cloud cover dataset. For the purpose of evaluating model performance at the submonthly (daily) time scale we also employ the E-OBS version 3.0 temperature dataset (Haylock et al., 2008).

The global $1^{\circ}$ gridded dataset from the Global Soil Wetness Project (GSWP-2) (Dirmeyer et al., 2006) is also used in this study. This product is based on 13 LSMs which were all driven by the same observationally-based meteorological forcing for the period 1986-1995. We consider the multimodel mean from the GSWP-2 dataset as well as the multimodel standard deviation. We used $\pm 2 \times$ std as an estimate of the uncertainty range of the GSWP-2 dataset.

Observations of diffuse and direct shortwave radiation from three stations (Carpentras, Toravere and Payerne) within the BSRN (Baseline Surface Radiation Network) network (Ohmura et al., 1998) are used. The raw measurements were processed to derive monthly means using the procedure described in Roesch et al. (2011).

For the specific purpose of evaluating the sensitivity of evapotranspiration to light partitioning, we use data from the Hyytiälä (Finland) FLUXNET site (Suni et al., 2003). This site was chosen because it has the longest record of diffuse radiation measurements along with evapotranspiration measurements compared to other European sites. The site is located at $181 \mathrm{~m}$ over an evergreen needleleaf forest $\left(24.29^{\circ} \mathrm{E}\right.$ $\left.61.85^{\circ} \mathrm{N}\right)$. We use non-gap-filled radiation and evapotranspiration data from the period 2002-2005.

No corrections are applied to any of the datasets. For comparison, model outputs are interpolated onto the respective dataset grids and in the case of point-scale measurements (i.e., BSRN and FLUXNET) the model grid cell encompassing the site coordinates is considered. When results are presented over specific regions, the European sub-domains as defined in the PRUDENCE project are used (Christensen et al., 2007). 
Table 1. Summary of the different experiments analysed in this study

\begin{tabular}{lccl}
\hline Experiment name & Atmospheric component & LSM & Other comments \\
\hline v4.0-TERRA_ML & 4.0 & TERRA_ML & same as experiment COSMO-CLM in Davin et al. (2011) \\
v4.0-CLM3.5 & 4.0 & CLM3.5 & same as experiment COSMO-CLM ${ }^{2}$ in Davin et al. (2011) \\
v4.8-TERRA_ML & 4.8 & TERRA_ML & \\
v4.8-CLM3.5 & 4.8 & CLM3.5 & \\
v4.8-CLM3.5-dif & 4.8 & CLM3.5 & same as experiment v4.8-CLM3.5 except that downward diffuse \\
& & & and direct components are explicitly passed to CLM3.5 instead \\
& & & of assuming a fixed diffuse/direct partitioning \\
\hline
\end{tabular}
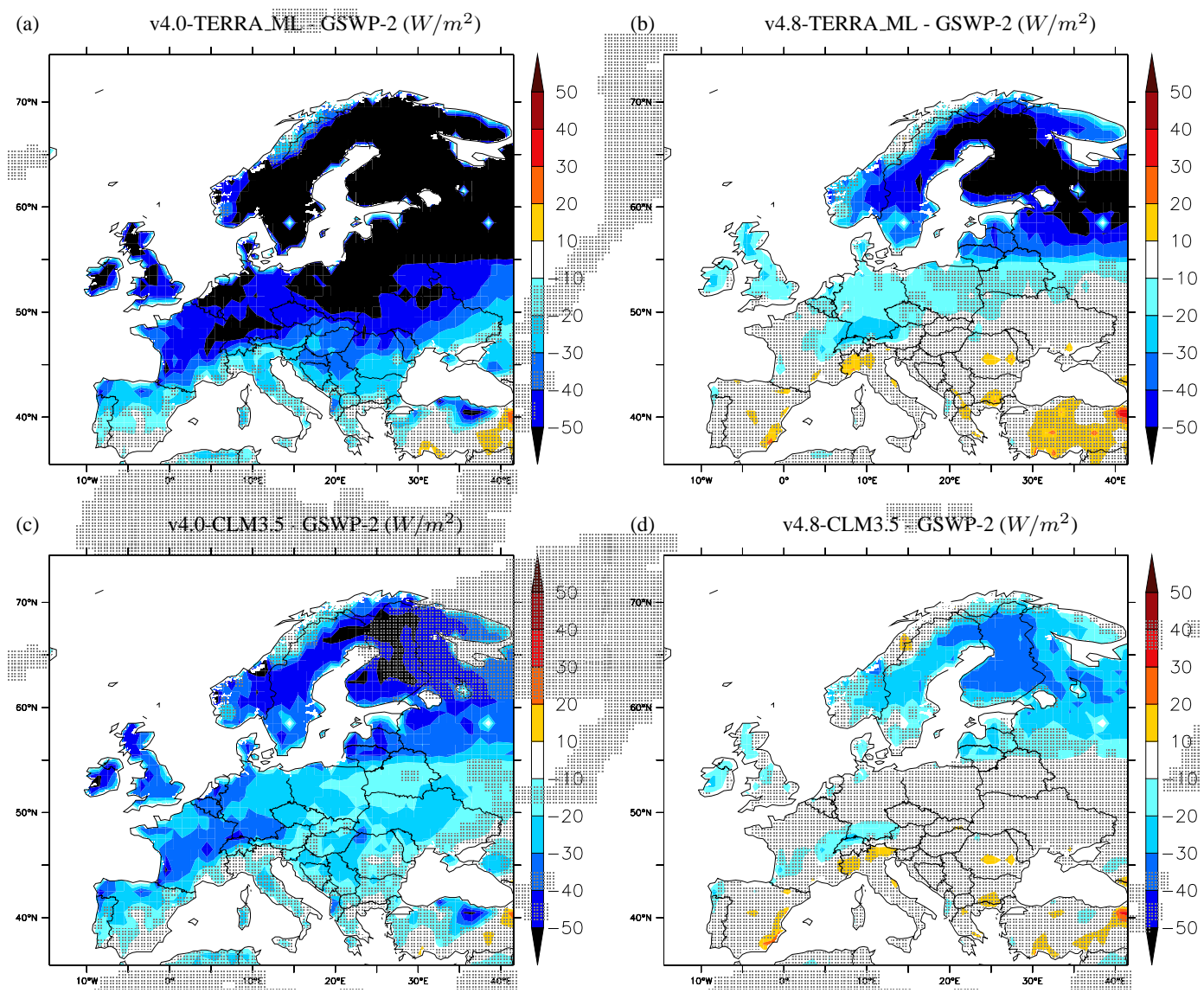

Fig. 1. Summer (JJA) mean net shortwave radiation bias (model minus GSWP-2) for the different experiments. The considered time period is 1986-1995 and areas where the model bias is within the GSWP-2 uncertainty range are indicated with grey shading.

\section{Results}

\subsection{Overall influence of the LSM}

\subsubsection{Radiation and clouds}

Biases in radiation and cloud cover for experiments v4.0TERRA_ML, v4.0-CLM3.5, v4.8-TERRA_ML and v4.8CLM3.5 are shown in Figs. 1, 2 and 3 for the summer season. Davin et al. (2011) analysed simulations v4.0-TERRA_ML and v4.0-CLM3.5 and found an improvement in surface net shortwave radiation (shown here in Fig. 1a and c) when using CLM3.5 instead of TERRA_ML. Despite this improvement, a pronounced shortwave radiation underestimation still remains in the model. Results from experiments v4.8TERRA_ML and v4.8-CLM3.5 indicate a positive influence of the new version of the atmospheric component (Fig. 1b and d), which further alleviates the shortwave radiation bias.

These successive improvements in surface net shortwave radiation can be traced back to the simulated cloud cover, since surface albedo does not vary strongly between the different experiments (not shown). Because of the inherent 
(a)

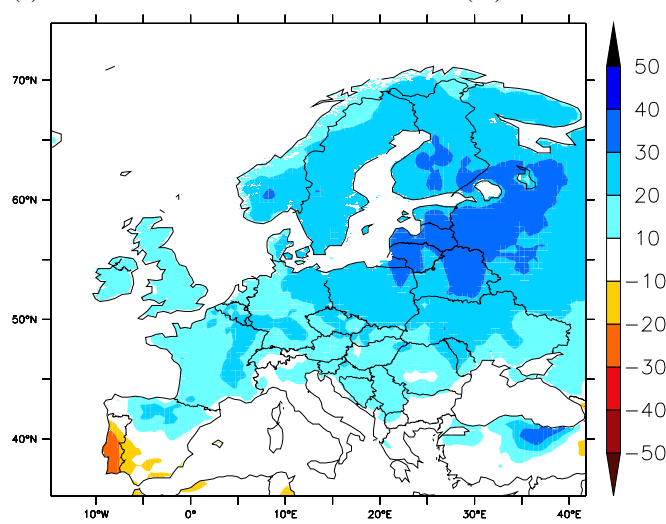

(c)

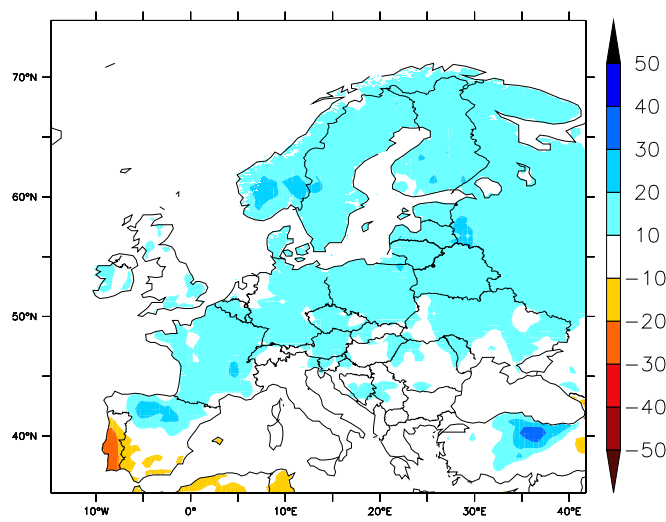

(b)

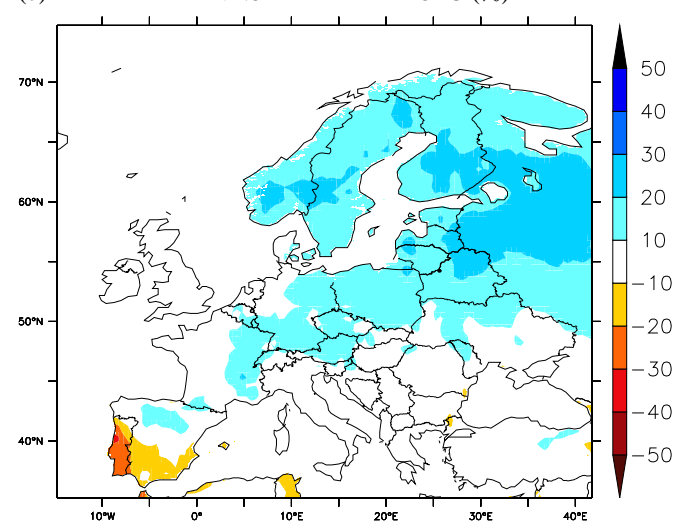

(d)

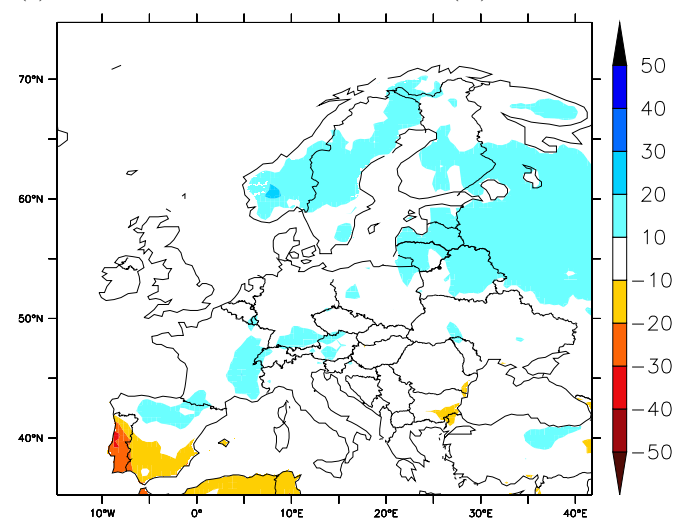

Fig. 2. Summer (JJA) mean cloud cover bias (model minus CRU) for the different experiments. The considered time period is $1986-1995$.

uncertainties in observed cloud cover, we use two different datasets to evaluate cloud cover biases in the model (Fig. 2 and 3). The amplitude of the inferred biases clearly depends on the reference dataset used, nevertheless the results remain qualitatively similar. Figures $2 \mathrm{a}$ and $3 \mathrm{a}$ show a large overestimation of total cloud cover in simulation v4.0-TERRA_ML, which explains the associated shortwave radiation underestimation. CLM3.5 as well as the new version of the atmospheric component both improve simulated fractional cloud cover, thus alleviating the preexisting shortwave radiation bias.

Davin et al. (2011) demonstrated that the effect of CLM3.5 on cloud cover is due to a better partitioning of latent versus sensible heat compared to TERRA_ML (with TERRA_ML overestimating latent heat relative to sensible heat). Switching from the old to the new atmospheric scheme also has a positive impact on the simulated cloud cover (Figs. 2b and $3 b)$. Several model improvements and corrections are responsible for this positive influence. In particular, the revised implementation of the Tiedtke convection scheme may play an important role as suggested by an additional simulation performed with an intermediate model version (v4.4TERRA_ML). This model version, in which the revisions to the Tiedtke scheme were first introduced, has already very similar characteristics as v4.8-TERRA_ML in terms of the simulated cloudiness (not shown) suggesting that the revised Tiedtke scheme is the main factor leading to the improved fractional cloud cover. It is worth mentioning that the convection scheme itself does not affect directly the simulated cloudiness which is calculated diagnostically in the model. The improved cloud cover is thus an indirect consequence of the modified convection scheme, the modified convective activity influencing the state of the atmosphere and subsequently cloudiness.

\subsubsection{Temperature and precipitation}

To obtain a quantitative estimate of the model performance in simulating 2-meter temperature and precipitation, we use an RMSE-based score accounting for spatial, seasonal and interannual variability (Fig. 4). For each European sub-domain, the RMSE is calculated from the difference (model minus CRU) taken at each grid cell and for each month (monthly means) over the period 1986-2006.

For most regions, the best scores are reached with experiments v4.8-CLM3.5 including CLM3.5 instead of TERRA_ML and the new version of the atmospheric component. Moreover, the LSM contribution to the bias reduction 

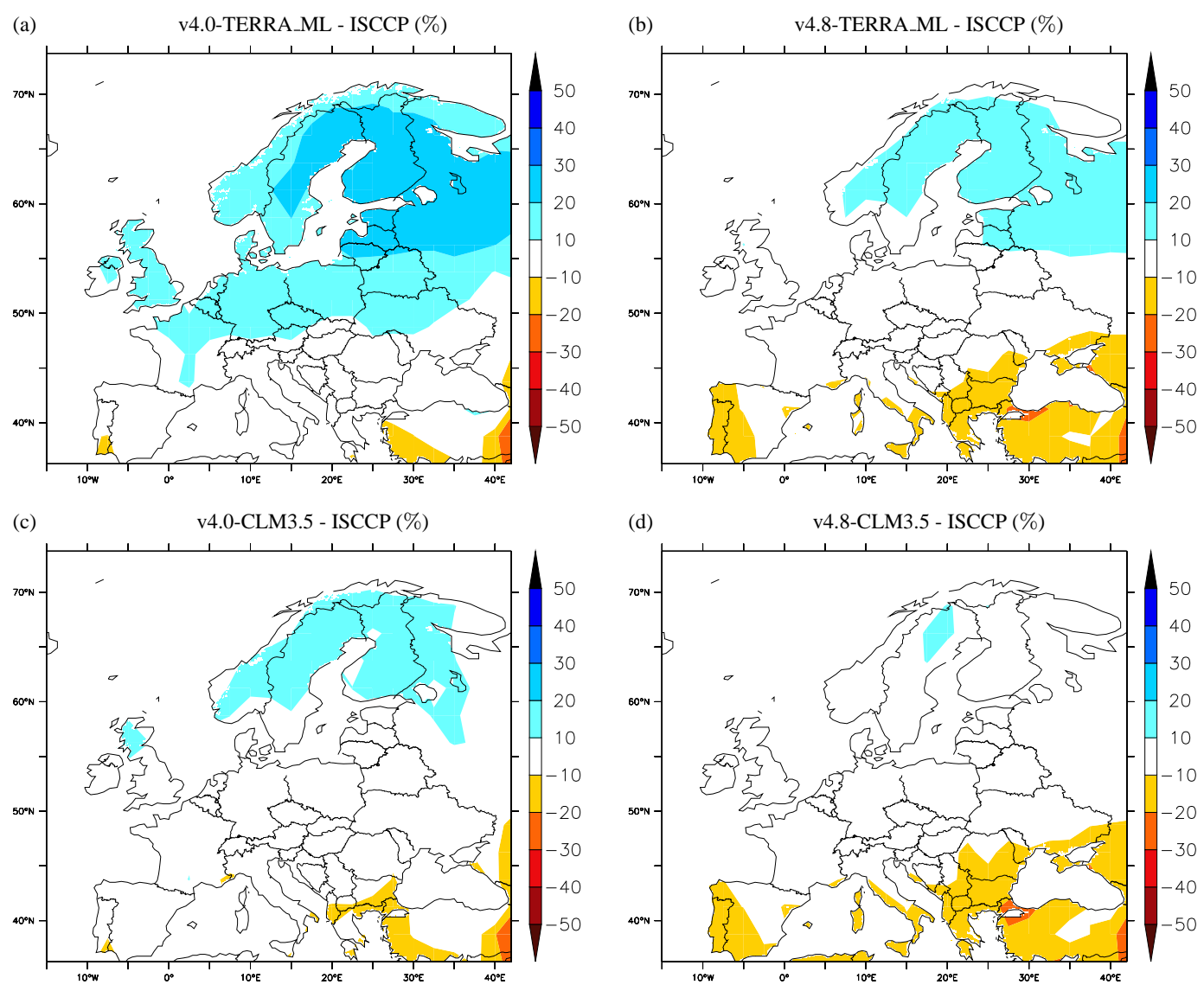

Fig. 3. Same as Fig. 2 but in reference to ISCCP instead of CRU.

is of the same order as the contribution of the atmospheric component, highlighting the overall importance of the LSM for the quality of the simulation. The positive influence of CLM3.5 is particularly important for temperature and less marked for precipitation. The effect on precipitation is dominated by the atmospheric component, whereas for temperature the LSM has the most impact.

\subsection{Role of diffuse/direct radiation partitioning}

We focus now on the influence of diffuse/direct radiation partitioning on surface fluxes and climate. In experiment v4.8CLM3.5-dif, the ratio of diffuse to direct light as seen by CLM3.5 is allowed to vary spatially and temporally. We compare v4.8-CLM3.5-dif to experiment v4.8-CLM3.5 in which CLM3.5 instead assumes a constant diffuse to direct ratio.

In the following, we first evaluate the ability of the model to realistically represent the partitioning of diffuse versus direct light (through the radiative transfer scheme of the atmospheric component). Then, we examine the sensitivity of CLM3.5 to light partitioning and compare it to observations. Finally, we analyse the effect of these processes on the mean climate and climate variability in the model.

\subsubsection{Evaluation of diffuse/direct partitioning}

Figure 5 shows time series of diffuse fraction (ratio of incoming diffuse light to total incoming shortwave radiation at the surface) for three different European sites. Observations are from the BSRN network and modeled values correspond to the radiation partitioning as seen by CLM3.5. In the case of experiment v4.8-CLM3.5, this partitioning is set to a constant value of $30 \%$ diffuse radiation whereas in experiment v4.8-CLM3.5-dif the radiation partitioning comes as an input from the atmospheric component (through provision of both diffuse and direct radiation fluxes instead of the total incoming shortwave radiation as in experiment v4.8-CLM3.5).

For all 3 sites, the $30 \%$ diffuse radiation partitioning appears to be on average too low compared to observations and, furthermore, it does not account for the large seasonal and interannual variations seen in observations. On the other hand, the partitioning in experiment v4.8-CLM3.5-dif is in good agreement with observations. In particular the seasonal cycle (more diffuse light in winter than in summer) is well represented and some features of the interannual variability are also captured. 

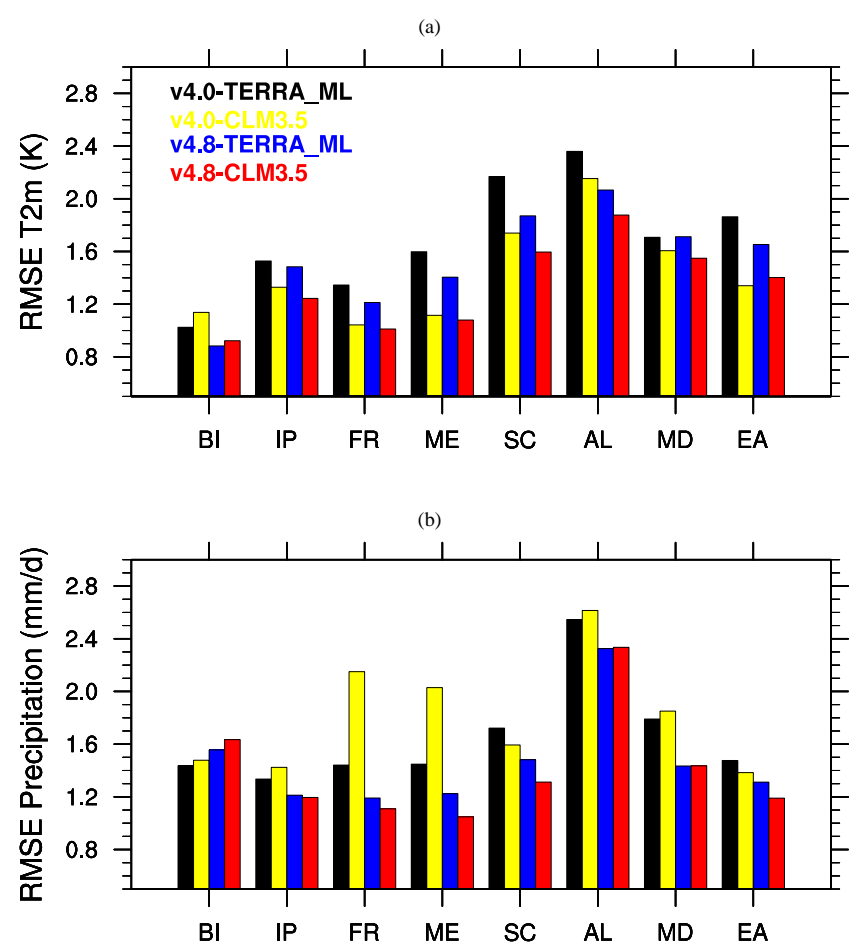

Fig. 4. Model performance for (a) 2-meter temperature and b) precipitation, for the different model experiments. BI: British Isles; IP: Iberian Peninsula; FR: France; ME: Mid-Europe; SC: Scandinavia; AL: Alps; MD: Mediterranean; EA: Eastern Europe. The considered score is the RMSE calculated from the differences (model minus CRU) taken at each grid cell and for each month (monthly means) over the time period 1986-2006.

These results indicate that providing separately the incoming diffuse and direct components to CLM3.5 represents a real improvement compared to the default fixed partitioning used in CLM3.5. We note, however, a tendency of experiment v4.8-CLM3.5-dif to overestimate diffuse fraction (particularly at Carpentras), which might be caused by a too high aerosol optical depth in the model. The aerosol climatology prescribed in the model is indeed known to overestimate aerosol optical depth over Europe (Zubler et al., 2011).

\subsubsection{Evapotranspiration response to diffuse/direct partitioning}

Observations suggest that plants tend to be photosynthetically more active under diffuse light conditions (Gu et al., 2003; Alton et al., 2007). Considering the tight coupling between photosynthesis and transpiration and the fact that transpiration is the main contributor to land evapotranspiration (Dirmeyer et al., 2006), light partitioning is also expected to affect water fluxes (Knohl and Baldocchi, 2008; Oliveira et al., 2011).

We analyse observational data from a flux measurement site to examine the sensitivity of latent heat to diffuse ver- sus direct light conditions (Fig. 6a). The latent heat flux is plotted against incoming shortwave radiation, showing the increase in latent heat with increasing radiation. We further discriminate between diffuse and direct conditions based on the observed diffuse fraction and choosing a threshold of diffuse fraction above $65 \%$ and below $35 \%$ to represent diffuse and direct conditions, respectively. For a given amount of incoming radiation, the measured latent heat flux tends to be larger under diffuse conditions. This behaviour is qualitatively and quantitatively well reproduced by the model (experiment v4.8-CLM3.5-dif in Fig. 6a). To help understand the underlying mechanism, we examine the sensitivity of the individual evapotranspiration components in the model (Fig. 6b). Both transpiration and canopy evaporation (from intercepted water) are increased under diffuse light conditions, due to the more homogeneous distribution of radiation within the canopy with higher diffuse light. This shows that the overall evapotranspiration sensitivity to light partitioning comes from these two components and not from ground evaporation.

This comparison with observed data gives an indication that canopy processes are realistically represented in CLM3.5 and that the sensitivity of evapotranspiration to light partitioning is relatively well captured. However, this comparison is limited to a single site, due to the limited availability of relatively long time series of both diffuse light and evapotranspiration at other sites. The site considered here (boreal evergreen needleleaf forest) may not be representative of other ecosystems and future work will be needed to expand such model/data comparison to other ecosystem types and climate zones.

\subsubsection{Effect on the mean climate state}

Figure 7 displays differences between experiments v4.8CLM3.5 and v4.8-CLM3.5-dif for various surface variables. Since no significant differences are found in winter (not shown), we analyse only the summer season. The fraction of diffuse light is increased in experiment v4.8-CLM3.5-dif compared to the prescribed (30\%) diffuse/direct ratio in experiment v4.8-CLM3.5 (Fig. 7a). This increase is more pronounced at high latitudes since the diffuse fraction increases with latitude. As a consequence, photosynthesis is enhanced in experiment v4.8-CLM3.5-dif (Fig. 7b). Transpiration also increases (Fig. 7d), but in line with earlier observational evidence (Knohl and Baldocchi, 2008), the relative increase in transpiration is smaller than the photosynthesis increase (Figs. 7b and d) implying a rise in plant's water use efficiency with increasing diffuse light. Finally, total evapotranspiration (Fig. 7c) tends to increase as well but in smaller proportions compared to transpiration, due to a compensating effect from ground evaporation (not shown).

The 2-meter temperature is decreased in experiment $\mathrm{v} 4.8$ CLM3.5-dif compared to v4.8-CLM3.5 (Fig. 7f). This temperature decrease reflects the change in evaporative fraction 

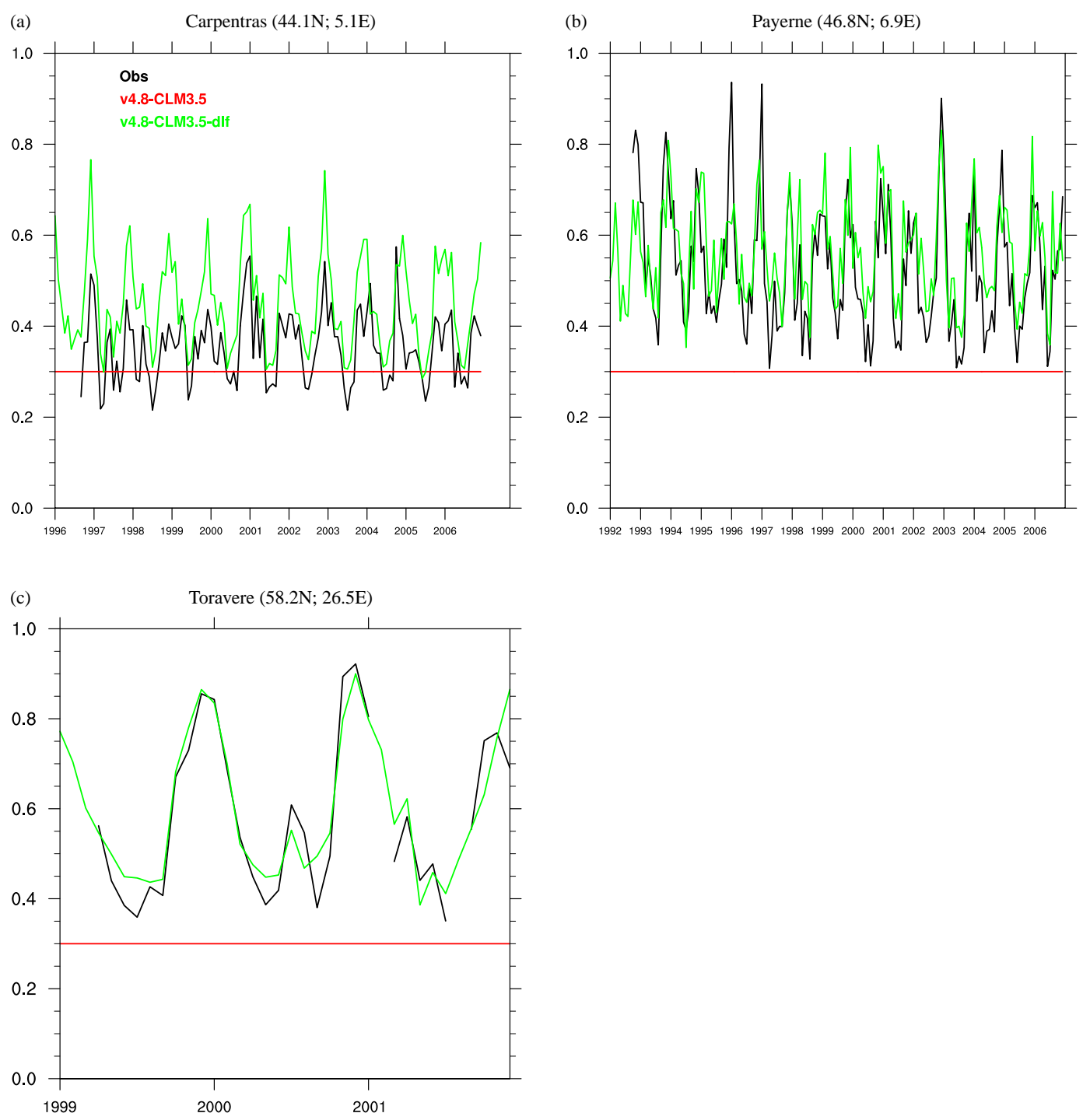

Fig. 5. Time series of diffuse light fraction (monthly means) at three different BSRN sites.

(Fig. 7e), with more diffuse light leading to enhanced evapotranspiration and consequently reduced sensible heating thus lowering surface temperature. This cooling effect improves the simulated summer mean temperature in experiment $v 4.8$ CLM3.5-dif by slightly reducing the warm bias present in experiment v4.8-CLM3.5 (Fig. 8).

\subsubsection{Implications for climate variability}

Variations in the diffuse/direct ratio at the surface can influence evapotranspiration and the surface energy balance and can thus induce variations in temperature and other climate variables. By accounting for this process, experiment v4.8CLM3.5-dif incorporates an additional source of variability compared to experiment v4.8-CLM3.5. To assess the added value of taking this process into account, we analyse the model skill in simulating 2-meter temperature variability at the monthly and daily time scales. Based on time series aggregated over 8 sub-domains and focusing on the summer season, we calculate the squared correlations $\left(R^{2}\right)$ between model and observations, using either monthly or daily averages (Table 2). $R^{2}$ values are found to be higher in experiment v4.8-CLM3.5-dif for all regions (except for BI where there is no change in the $R^{2}$ value between v4.8-CLM3.5 and v4.8-CLM3.5-dif). $R^{2}$ values are overall higher at the monthly time scale in both experiments, but the increase in $R^{2}$ values in experiment v4.8-CLM3.5-dif, which ranges between $0-3 \%$, is of similar magnitude for both monthly and daily time scales. In other words, comparing experiments v4.8-CLM3.5 and v4.8-CLM3.5-dif suggests that variations in diffuse/direct partitioning may explain up to $3 \%$ of the summer temperature variability at the monthly and daily time 
(a)

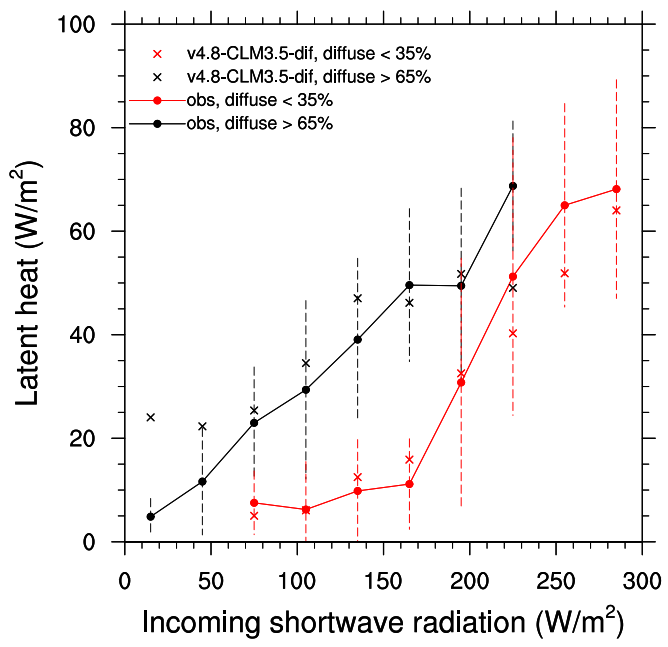

(b)

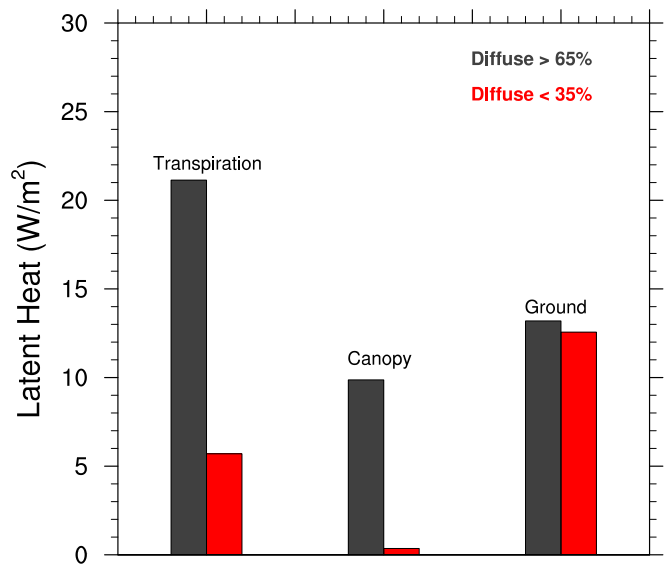

Fig. 6. Latent heat response (observed and simulated) to diffuse/direct light conditions at the Hyytiälä site. a) Latent heat evolution as a function of incoming shortwave radiation for predominantly diffuse light conditions (black) and predominantly direct light conditions (red). The points represent the mean latent heat for specific radiation bins based daily means over the period 2002-2005 restricted to spring and summer (growing season). The standard deviation of the observation is also shown. Diffuse and direct conditions are defined as diffuse light fraction above $65 \%$ and below $35 \%$, respectivelly. b) Individual evapotranspiration components in the model and their sensitivity to light conditions. The plotted values are averaged over the 100-200 shortwave radiation range using the same underlying data as for a).

Table 2. Squared correlation $\left(R^{2}\right)$ between modeled and observed (E-OBS) 2-meter temperature. Time series are domain-averaged over eight different regions as defined in Fig. 4. Correlations are based either on monthly or daily means in both cases considering only data between June and August.

\begin{tabular}{lcccccccc}
\hline Experiment & BI & IP & FR & ME & SC & AL & MD & EA \\
\hline & \multicolumn{8}{c}{ monthly time scale } \\
v4.8-CLM3.5 & 0.92 & 0.90 & 0.87 & 0.89 & 0.88 & 0.85 & 0.82 & 0.71 \\
v4.8-CLM3.5-dif & 0.92 & 0.91 & 0.88 & 0.90 & 0.91 & 0.88 & 0.85 & 0.74 \\
& \multicolumn{7}{c}{ daily time scale } \\
v4.8-CLM3.5 & 0.79 & 0.86 & 0.82 & 0.82 & 0.72 & 0.80 & 0.72 & 0.73 \\
v4.8-CLM3.5-dif & 0.79 & 0.87 & 0.84 & 0.83 & 0.74 & 0.82 & 0.74 & 0.75 \\
\hline
\end{tabular}

scales. We note that a similar analysis for precipitation (not shown) leads to inconclusive results.

To put these results in a more general context, we compare the impact of diffuse/direct partitioning alone versus the overall impact of changing the LSM on temperature variability. The model performance in terms of standard deviation (normalized) and correlation is shown for experiments v4.8-TERRA_ML, v4.8-CLM3.5 and v4.8-CLM3.5dif in the form of a Taylor diagram (Fig. 9). Over most regions and at both monthly and daily time scales, temperature variability is reduced (and often closer to observations) when using CLM3.5 instead of TERRA_ML. Accounting for variations in diffuse/direct ratio at the surface (v4.8-CLM3.5 compared to v4.8-CLM3.5-dif) tends to improve the model performance in terms of correlation with observations. It also slightly increases temperature variability for the majority of regions, which is in line with incorporating an additional source of variability. But the overall influence on temperature variability remains quantitatively modest in view of the bigger impact brought about by the full replacement of the LSM.

\section{Conclusions}

By testing two alternative LSMs within a RCM, this study quantitatively addresses the role of land processes in simulating regional climate over Europe. We use the COSMO-CLM RCM either with its native LSM (TERRA_ML) or coupled to the more advanced CLM3.5. In a previous study based on COSMO-CLM version 4.0, Davin et al. (2011) found improvements in the simulated climate over Europe when using CLM3.5, owing to more realistic surface fluxes in CLM3.5 compared to TERRA_ML. Here, we present evidence of the 
(a)

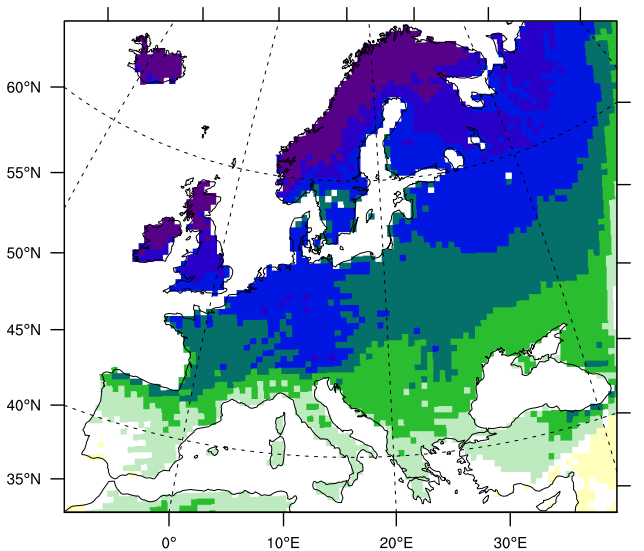

(c) Evapotranspiration

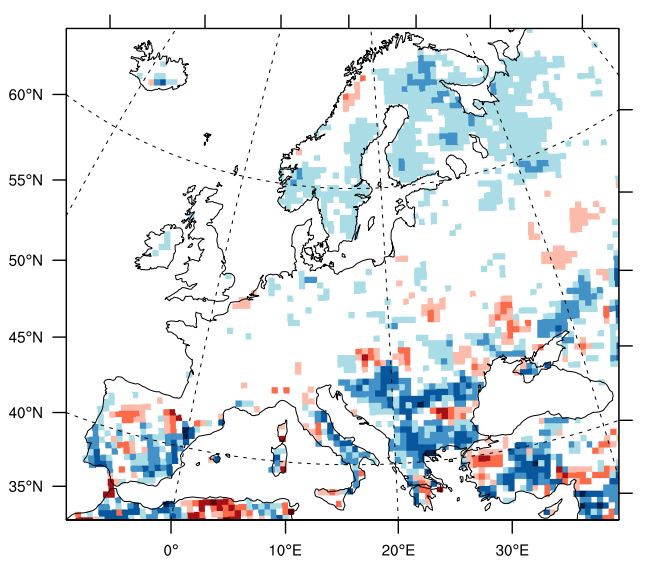

(e)

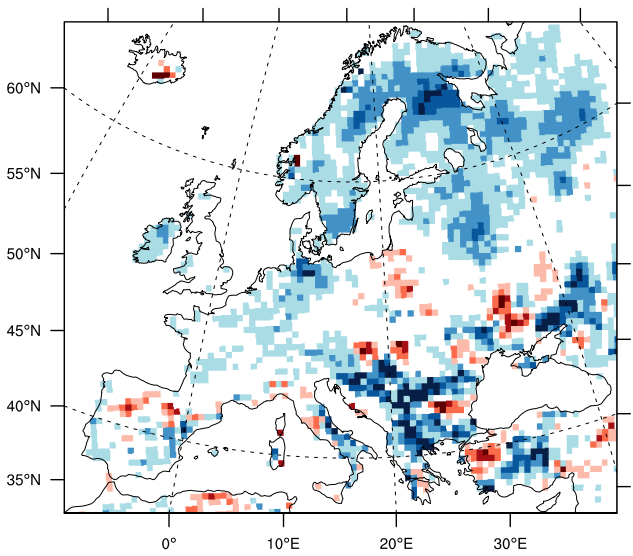

(b)

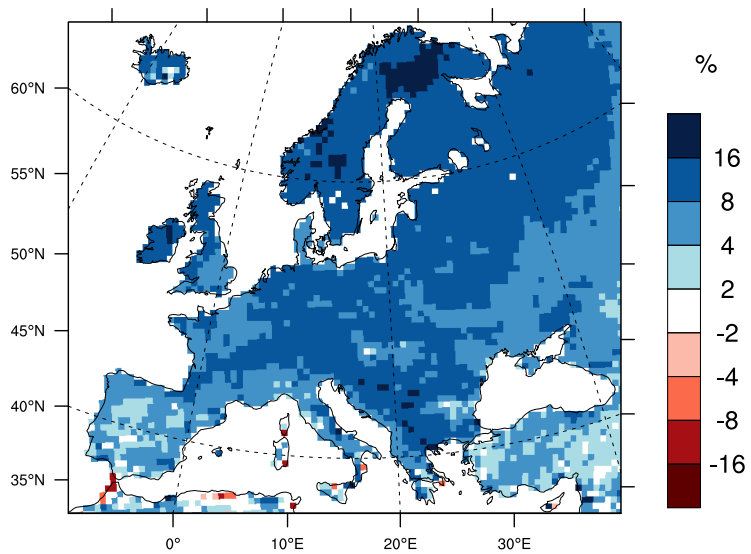

(d)

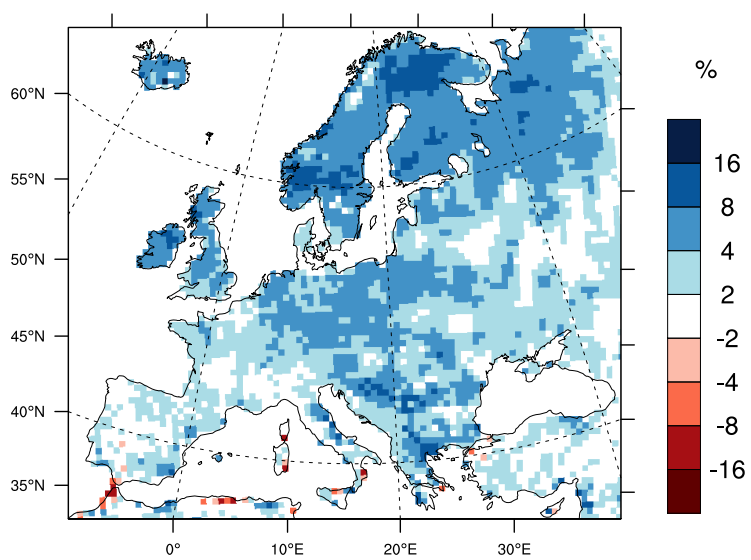

(f) 2-m temperature

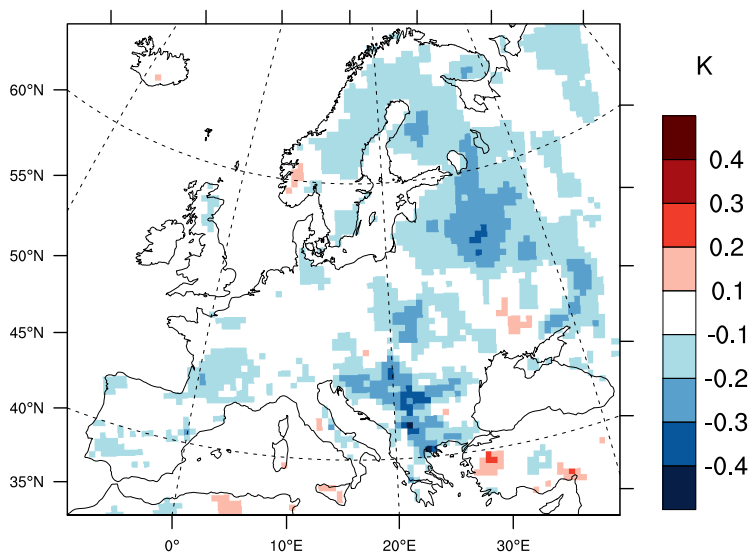

Fig. 7. Summer (JJA) mean change (v4.8-CLM3.5-dif minus v4.8-CLM3.5) for a) diffuse fraction (\%), b) photosynthesis (relative change), c) evapotranspiration (relative change), d) transpiration (relative change), e) evaporative fraction (\%) and f) 2-meter temperature (K). The considered time period is 1986-2006.

robustness of this conclusion by showing that the positive effect of CLM3.5 remains true in the context of a new improved version of COSMO-CLM (version 4.8). Moreover, we show that the influence of the LSM on the simulated climate can be typically as large as that from the atmospheric component, at least in summer. This is particularly the case for near-surface temperature, while precipitation is more affected by changes in the atmospheric component. These results are also in line with previous numerical experiments suggesting that a significant fraction of summer temperature 
(a)

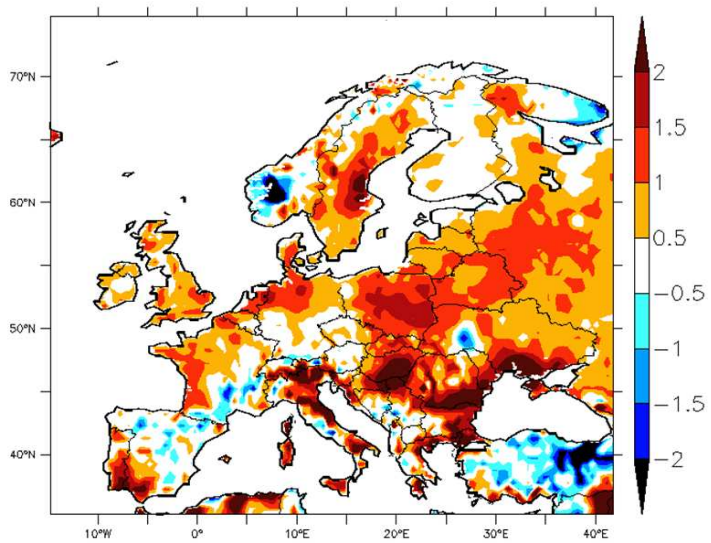

(b)

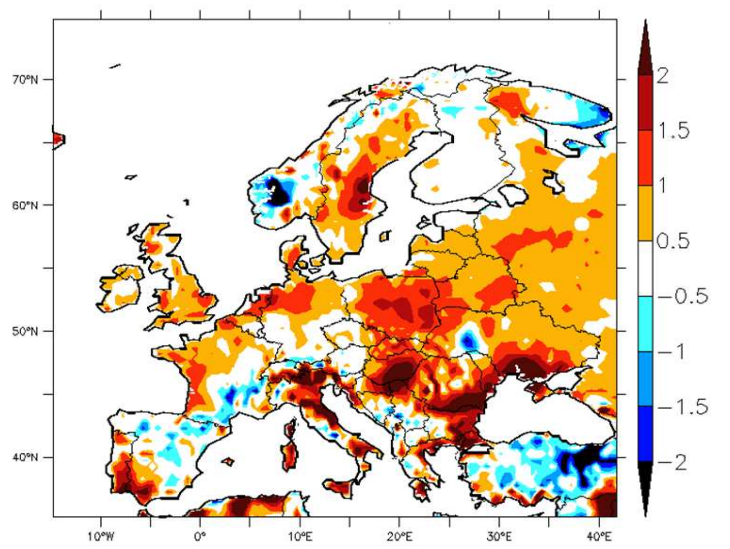

Fig. 8. Summer (JJA) mean 2-meter temperature bias (model minus CRU) for experiments v4.8-CLM3.5 and v4.8-CLM3.5-dif. The considered time period is $1986-2006$.
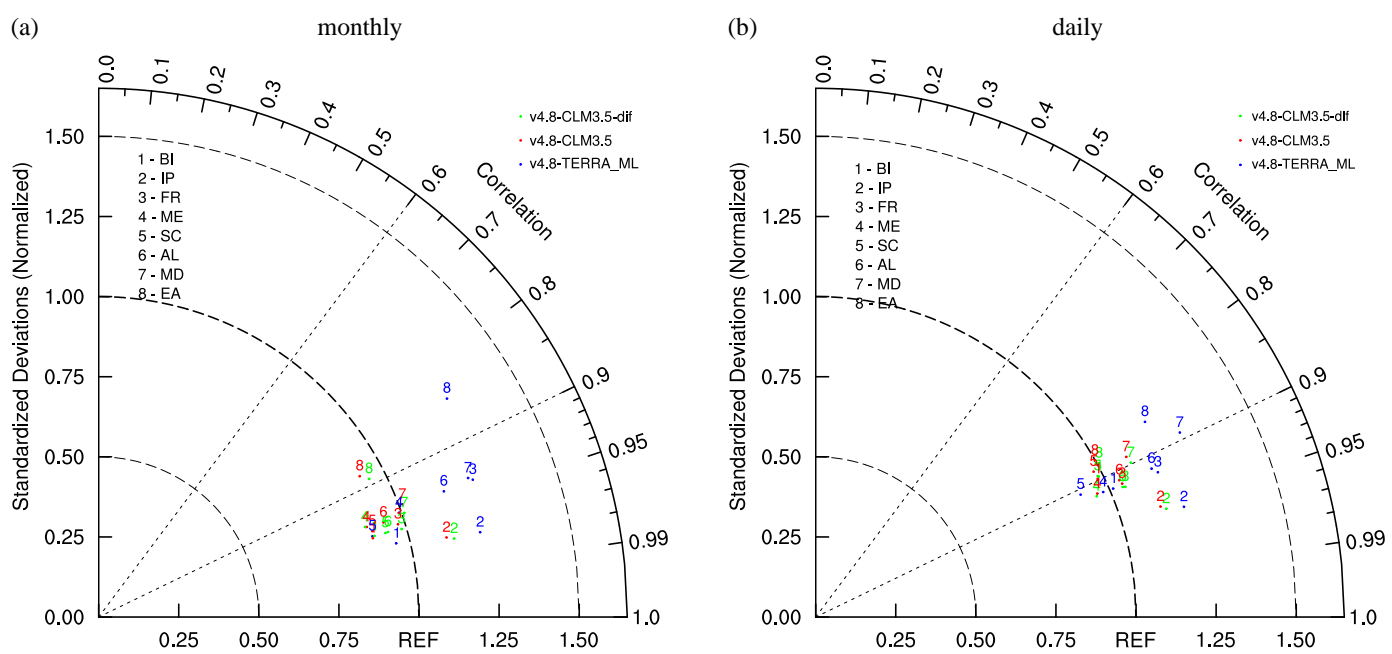

Fig. 9. Taylor diagram for 2-meter temperature displaying the correlation and ratio of variance (normalized standard deviation) in reference to E-OBS. The statistics are shown for different regions and are based on a) monthly and b) daily means for the summer period (JJA).

variability can be attributed to soil moisture feedbacks in Europe (Seneviratne et al., 2006; Jaeger and Seneviratne, 2011). Overall, the best model performance is achieved when the more advanced LSM (CLM3.5 instead of TERRA_ML) is combined with the improved version of the atmospheric component (v4.8 instead v4.0). In this case, the substantial underestimation of surface net shortwave radiation which was noted as a remaining deficiency in the previous version of COSMO-CLM ${ }^{2}$ (Davin et al., 2011) is largely alleviated. One central aspect allowing for the noted improvements is the simulated cloudiness, which is positively affected on one hand by the better partitioning of surface fluxes in CLM3.5 and on the other hand by the revised convection scheme included in COSMO-CLM version 4.8.

We furthermore explore the impact of diffuse/direct radiation partitioning on surface fluxes and climate and its po- tential added value in regional simulations. An experiment where the diffuse and direct radiation components are explicitly provided to CLM3.5 (instead of a fixed diffuse/direct ratio) is performed. Comparison with observations shows that the model, through its atmospheric radiative transfer scheme, realistically captures seasonal and interannual variations in diffuse/direct radiation partitioning at the surface. Moreover, the increase in evapotranspiration under diffuse light conditions seen in eddy-flux measurements is also captured by CLM3.5. Taking explicitly into account variations in light partitioning at the surface improves the simulated summer temperature variability both at the monthly and the daily time scales across most regions. A small fraction (up to $3 \%$ ) of the overall variability in surface temperature can be attributed to diffuse/direct light variations in our experiments. Our experiments also show that the average level of diffuse radiation 
can strongly impact the partitioning between latent and sensible heat with consequences on surface temperature. It is worth mentioning that canopy processes in the Community Land Model, in particular radiative transfer in the canopy, have been recently revised (Bonan et al., 2011). Although this version is not yet available, a future reassessment of our conclusions using these new developments may help quantifying modelling uncertainties attached to these processes.

Acknowledgements. We are grateful to Gordon Bonan and Dmitrii Mironov for their useful comments on the manuscript. We thank Timo Vesala for allowing access to the Hyytiälä (FIHyy) flux data. The computing time was provided by the Swiss National Supercomputing Centre (CSCS). This research has been supported by the Competence Center Environment and Sustainability of the ETH Domain (CCES) through the MAIOLICA project.

Edited by: G. Wohlfahrt

\section{References}

Alton, P. B., North, P. R., and Los, S. O.: The impact of diffuse sunlight on canopy light-use efficiency, gross photosynthetic product and net ecosystem exchange in three forest biomes, Global Change Biol., 13, 776-787, doi:10.1111/j.13652486.2007.01316.x, 2007.

Arneth, A., Harrison, S. P., Zaehle, S., Tsigaridis, K., Menon, S., Bartlein, P. J., Feichter, J., Korhola, A., Kulmala, M., O’Donnell, D., Schurgers, G., Sorvari, S., and Vesala, T.: Terrestrial biogeochemical feedbacks in the climate system, Nat. Geosci., 3, 525532, doi:10.1038/ngeo905, 2010.

Baldauf, M., Seifert, A., Förstner, J., Majewski, D., Raschendorfer, M., and Reinhardt, T.: Operational convective-scale numerical weather prediction with the COSMO model: description and sensitivities, Mon. Weather Rev., doi:10.1175/MWR-D-10-05013.1, 2011.

Bonan, G. B.: Forests and climate change: Forcings, feedbacks, and the climate benefits of forests, Science, 320, 1444-1449, doi:10.1126/science.1155121, 2008.

Bonan, G. B., Lawrence, P. J., Oleson, K. W., Levis, S., Jung, M., Reichstein, M., Lawrence, D. M., and Swenson, S. C.: Improving canopy processes in the Community Land Model version 4 (CLM4) using global flux fields empirically inferred from FLUXNET data, J. Geophys. Res., 116, doi:doi:10.1029/2010JG001593, 2011.

Christensen, J. H., Carter, T. R., Rummukainen, M., and Amanatidis, G.: Evaluating the performance and utility of regional climate models: the PRUDENCE project, Clim. Change, 81, 1-6, doi:10.1007/s10584-006-9211-6, 2007.

Davin, E. L., Stoeckli, R., Jaeger, E. B., Levis, S., and Seneviratne, S. I.: COSMO-CLM ${ }^{2}$ : a new version of the COSMO-CLM model coupled to the Community Land Model, Clim. Dyn., 37, 1889-1907, doi:10.1007/s00382-011-1019-z, 2011.

Denning, A., Nicholls, M., Prihodko, L., Baker, I., Vidale, P., Davis, K., and Bakwin, P.: Simulated variations in atmospheric $\mathrm{CO} 2$ over a Wisconsin forest using a coupled ecosystem-atmosphere model, Global Change Biol., 9, 1241-1250, 2003.

Dirmeyer, P. A., Gao, X., Zhao, M., Guo, Z., Oki, T., and Hanasaki, N.: GSWP-2 - Multimodel anlysis and implications for our perception of the land surface, Bull. Amer. Meteorol. Soc., 87, 1381+, doi:10.1175/BAMS-87-10-1381, 2006.

Friedlingstein, P., Cox, P., Betts, R., Bopp, L., Von Bloh, W., Brovkin, V., Cadule, P., Doney, S., Eby, M., Fung, I., Bala, G., John, J., Jones, C., Joos, F., Kato, T., Kawamiya, M., Knorr, W., Lindsay, K., Matthews, H. D., Raddatz, T., Rayner, P., Reick, C., Roeckner, E., Schnitzler, K. G., Schnur, R., Strassmann, K., Weaver, A. J., Yoshikawa, C., and Zeng, N.: Climate-carbon cycle feedback analysis: Results from the (CMIP)-M-4 model intercomparison, J. Clim., 19, 3337-3353, 2006.

Giorgi, F.: Regional climate modeling: Status and perspectives, J. Phys. IV, 139, 101-118, doi:10.1051/jp4:2006139008, 2006.

Grasselt, R., Schuettemeyer, D., Warrach-Sagi, K., Ament, F., and Simmer, C.: Validation of TERRA-ML with discharge measurements, Meteorol. Z., 17, 763-773, doi:10.1127/09412948/2008/0334, 2008.

Gu, L., Baldocchi, D., Wofsy, S., Munger, J., Michalsky, J., Urbanski, S., and Boden, T.: Response of a deciduous forest to the Mount Pinatubo eruption: Enhanced photosynthesis, Science, 299, 2035-2038, 2003.

Haylock, M. R., Hofstra, N., Tank, A. M. G. K., Klok, E. J., Jones, P. D., and New, M.: A European daily high-resolution gridded data set of surface temperature and precipitation for 1950-2006, J. Geophys. Res., 113, doi:10.1029/2008JD010201, 2008.

Jaeger, E. B. and Seneviratne, S. I.: Impact of soil moistureatmosphere coupling on European climate extremes and trends in a regional climate model, Clim. Dyn., 36, 1919-1939, doi:10.1007/s00382-010-0780-8, 2011.

Knohl, A. and Baldocchi, D. D.: Effects of diffuse radiation on canopy gas exchange processes in a forest ecosystem, J. Geophys. Res., 113, doi:10.1029/2007JG000663, 2008.

Lu, L., Pielke, R., Liston, G., Parton, W., Ojima, D., and Hartman, M.: Implementation of a two-way interactive atmospheric and ecological model and its application to the central United States, J. Clim., 14, 900-919, 2001.

Manabe, S.: Climate and Ocean Circulation.I. Atmospheric Circulation and Hydrology of Earths Surface, Mon. Weather Rev., 97, 739-774, 1969.

Mellor, G. L. and Yamada, T.: Hierarchy of turbulence closure models for planetary boundary-layers, J. Atmos. Sci., 31, 1791-1806, 1974.

Mellor, G. L. and Yamada, T.: Development of a turbulence closuremodel for geophysical fluid problems, Rev. Geophys., 20, 851875, 1982.

Mercado, L. M., Bellouin, N., Sitch, S., Boucher, O., Huntingford, C., Wild, M., and Cox, P. M.: Impact of changes in diffuse radiation on the global land carbon sink, Nature, 458, 1014-1017, doi:10.1038/nature07949, 2009.

Mitchell, T. and Jones, P.: An improved method of constructing a database of monthly climate observations and associated high-resolution grids, Int. J. Climatol., 25, 693-712, doi:10.1002/joc.1181, 2005.

Ohmura, A., Dutton, E., Forgan, B., Frohlich, C., Gilgen, H., Hegner, H., Heimo, A., Konig-Langlo, G., McArthur, B., Muller, G., Philipona, R., Pinker, R., Whitlock, C., Dehne, 
K., and Wild, M.: Baseline Surface Radiation Network (BSRN/WCRP): New precision radiometry for climate research, Bull. Amer. Meteorol. Soc., 79, 2115-2136, doi:10.1175/1520-

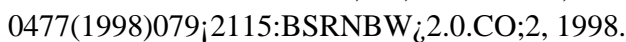

Oleson, K. W., Dai, Y., Bonan, G. B., Bosilovich, M., Dickinson, R. E., Dirmeyer, P., Hoffman, F., Houser, P., Levis, S., Niu, G. Y., Thornton, P. E., Vertenstein, M., Yang, Z. L., and Zeng, X.: Technical description of the Community Land Model (CLM), NCAR Tech. Note NCAR/TN-461+STR, Natl. Cent. for Atmos. Res., Boulder, Colo., 2004.

Oleson, K. W., Niu, G. Y., Yang, Z. L., Lawrence, D. M., Thornton, P. E., Lawrence, P. J., Stoeckli, R., Dickinson, R. E., Bonan, G. B., Levis, S., Dai, A., and Qian, T.: Improvements to the Community Land Model and their impact on the hydrological cycle, J. Geophys. Res., 113, doi:10.1029/2007JG000563, 2008.

Oliveira, P. J. C., Davin, E. L., Levis, S., and Seneviratne, S. I.: Vegetation-mediated impacts of trends in global radiation on land hydrology: a global sensitivity study, Global Change Biol., 17, 3453-3467, doi:10.1111/j.1365-2486.2011.02506.x, 2011.

Ritter, B. and Geleyn, J.: A comprehensive radiation scheme for numerical weather prediction models with potential applications in climate simulations, Mon. Weather Rev., 120, 303-325, 1992.

Rockel, B., Will, A., and Hense, A., eds.: Special Issue: Regional Climate Modelling With COSMO-CLM (CCLM), 17, Meteorol. Z., 2008.

Roesch, A., Wild, M., Ohmura, A., Dutton, E. G., Long, C. N., and Zhang, T.: Assessment of BSRN radiation records for the computation of monthly means (vol 4, pg 339, 2011), Atmos. Meas. Tech., 4, 973, doi:10.5194/amt-4-973-2011, 2011.

Rossow, W. and Schiffer, R.: Advances in understanding clouds from ISCCP, Bull. Amer. Meteorol. Soc., 80, 2261-2287, 1999.

Seneviratne, S. I., Luethi, D., Litschi, M., and Schaer, C.: Landatmosphere coupling and climate change in Europe, Nature, 443, 205-209, doi:10.1038/nature05095, 2006.

Seneviratne, S. I., Corti, T., Davin, E. L., Hirschi, M., Jaeger, E. B., Lehner, I., Orlowsky, B., and Teuling, A. J.: Investigating soil moisture-climate interactions in a changing climate: A review, Earth-Sci. Rev., 99, 125-161, doi:10.1016/j.earscirev.2010.02.004, 2010.

Steiner, A. L., Pal, J. S., Rauscher, S. A., Bell, J. L., Diffenbaugh, N. S., Boone, A., Sloan, L. C., and Giorgi, F.: Land surface coupling in regional climate simulations of the West African monsoon, Clim. Dyn., 33, 869-892, doi:10.1007/s00382-009-05436, 2009.
Subin, Z. M., Riley, W. J., Jin, J., Christianson, D. S., Torn, M. S., and Kueppers, L. M.: Ecosystem Feedbacks to Climate Change in California: Development, Testing, and Analysis Using a Coupled Regional Atmosphere and Land Surface Model (WRF3CLM3.5), Earth Interact., 15, doi:10.1175/2010EI331.1, 2011.

Suni, T., Rinne, J., Reissell, A., Altimir, N., Keronen, P., Rannik, U., Dal Maso, M., Kulmala, M., and Vesala, T.: Long-term measurements of surface fluxes above a Scots pine forest in Hyytiala, southern Finland, 1996-2001, Boreal Environ. Res., 8, 287-301, 2003.

Thornton, P. E. and Zimmermann, N. E.: An improved canopy integration scheme for a land surface model with prognostic canopy structure, J. Clim., 20, 3902-3923, doi:10.1175/JCLI4222.1, 2007.

Tiedtke, M.: a comprehensive mass flux scheme for cumulus parameterization in large-scale models, Mon. Weather Rev., 117, 1779-1800, 1989.

Uppala, S., Kallberg, P., Simmons, A., Andrae, U., Bechtold, V., Fiorino, M., Gibson, J., Haseler, J., Hernandez, A., Kelly, G., Li, X., Onogi, K., Saarinen, S., Sokka, N., Allan, R., Andersson, E., Arpe, K., Balmaseda, M., Beljaars, A., Van De Berg, L., Bidlot, J., Bormann, N., Caires, S., Chevallier, F., Dethof, A., Dragosavac, M., Fisher, M., Fuentes, M., Hagemann, S., Holm, E., Hoskins, B., Isaksen, L., Janssen, P., Jenne, R., McNally, A., Mahfouf, J., Morcrette, J., Rayner, N., Saunders, R., Simon, P., Sterl, A., Trenberth, K., Untch, A., Vasiljevic, D., Viterbo, P., and Woollen, J.: The ERA-40 re-analysis, Quart. J. Roy. Met. Soc., 131, 2961-3012, doi:10.1256/qj.04.176, 2005.

Wang, J.-W., Denning, A. S., Lu, L., Baker, I. T., Corbin, K. D., and Davis, K. J.: Observations and simulations of synoptic, regional, and local variations in atmospheric $\mathrm{CO}_{2}$, J. Geophys. Res., 112, doi:10.1029/2006JD007410, 2007.

Winter, J. M., Pal, J. S., and Eltahir, E. A. B.: Coupling of Integrated Biosphere Simulator to Regional Climate Model Version 3, J. Clim., 22, 2743-2757, doi:10.1175/2008JCLI2541.1, 2009.

Zubler, E. M., Lohmann, U., Luethi, D., and Schaer, C.: Intercomparison of aerosol climatologies for use in a regional climate model over Europe, Geophys. Res. Lett., 38, doi:10.1029/2011GL048081, 2011. 